\title{
Correction to: Life history traits and host-killing rate of Neochrysocharis formosa on Tuta absoluta
}

\author{
P. Guleria $\cdot$ P. L. Sharma $\cdot$ S. C. Verma $\cdot$ R. S. Chandel
}

Published online: 9 November 2020

(C) International Organization for Biological Control (IOBC) 2020

\section{Correction to:}

BioControl (2020) 65:401-411

https://doi.org/10.1007/s10526-020-10016-Z

There was an error in the originally published Fig. 4 .

The correct Fig. 4 is shown below.

e-mail: sharma.pl@ rediffmail.com 
Fig. 4 Age-specific hostkilling rate $\left(\mathrm{k}_{\mathrm{x}}\right)$ of $N$. formosa on different instars of T. absoluta

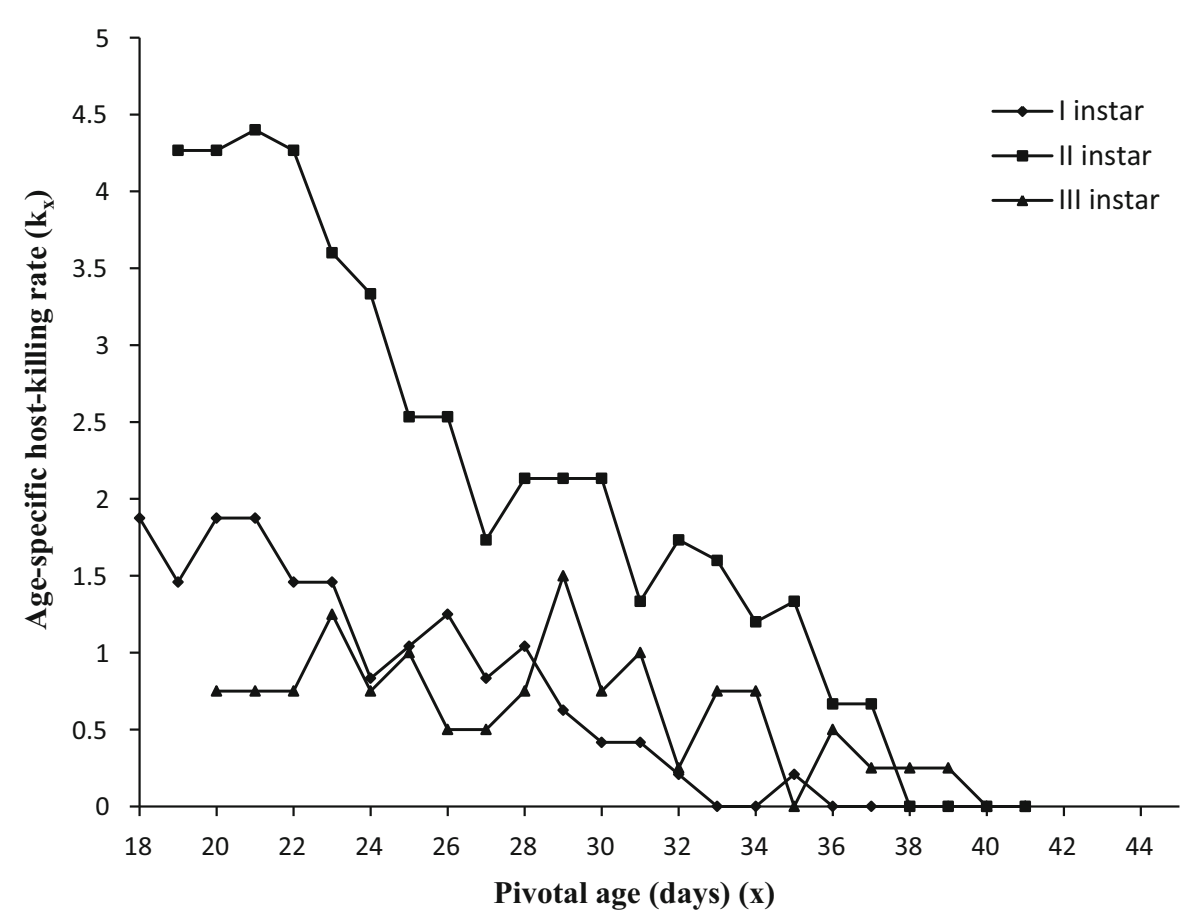

